\title{
Comparative Analysis of the Effects of Pressure on the Mechanical Properties and Microstructure of Die Cast Aluminum Alloys
}

\author{
Kenneth N. Obiekea*, Shekarau Y. Aku, Danjuma S. Yawas \\ Department of Mechanical Engineering, Ahmadu Bello University, Zaria, Nigeria \\ Email: *kenwood822002@yahoo.com
}

How to cite this paper: Obiekea, K.N., Aku, S.Y. and Yawas, D.S. (2016) Comparative Analysis of the Effects of Pressure on the Mechanical Properties and Microstructure of Die Cast Aluminum Alloys. Journal of Minerals and Materials Characterization ane Engineering, 4, 347-363.

http://dx.doi.org/10.4236/immce.2016.46029

Received: April 9, 2016

Accepted: November 18, 2016

Published: November 21, 2016

Copyright $\odot 2016$ by authors and Scientific Research Publishing Inc. This work is licensed under the Creative Commons Attribution International License (CC BY 4.0).

http://creativecommons.org/licenses/by/4.0/

\begin{abstract}
A study of the effects of pressure on the microstructure and mechanical properties of two aluminum alloys (A1350 and A380) was carried out and subsequent analysis made. Pressure was regulated at various levels in the die cast machine. Samples of both alloys were cast under varying regulated applied pressure. The mechanical properties of both alloy casts were tested and microstructure analysis done and the results compared for both alloys. The results obtained show that hardness, tensile strength, yield strength and impact strengths for both alloy cast samples followed similar pattern in the casting process. The hardness values increased with applied pressure but not too significantly in both alloy casts as pressure rose in the casting process. The yield strength of both alloy casts also increased with applied pressure. The impact strength and elongations also increased with applied pressure in both alloy casts. Also the microstructure analysis carried out on both alloy casts showed similar pattern of structural changes in the morphologies of both alloy casts as grains became fine as pressure rose from 350 to $1400 \mathrm{~kg} / \mathrm{cm}^{2}$. Models were developed for the results and for all the models developed, a close relationship with the experimental results were underlying in view of the small errors generated by them and can be used to predict the experimental values.
\end{abstract}

\section{Keywords}

Aluminum Alloys, Die Casting, Microstructure, Pressure

\section{Introduction}

Over the centuries, permanent metal mold processes continued to evolve and in the late 
18th century, processes were developed in which metal was injected into metal dies under pressure to manufacture metal parts. Doehler, H., [1] [2] is credited with developing die casting for the production of metal components in large volumes. Initially, only zinc alloys were used in die casting but demands for other metals drove the development of new die materials and process variants and by 1915 aluminum was being die cast in large quantities.

Much progress had been made in the development of die casting technologies over the last century. Developments continue to be made driving the capabilities of the process to new levels and increasing the integrity of die cast components. Cast aluminum products are in great use in various industrial sectors and more so in the aerospace industry where precision and high quality products are of utmost importance.

Essentially, die casting uses steel molds called dies into which molten metal is forced using extremely high pressure. Die casting is a versatile technique that allows for various levels of complexity in production, while still maintaining absolute precision to create a flawless end product.Researchers like Dargusch et al. [3] determined the effects of process variables on the quality of high pressure die cast components with the aid of in-cavity pressure sensors. In particular, the effects of set intensification pressure, delay time, and casting velocity were investigated and in turn the effect of variations in these parameters on the integrity of the final part, Porosity was found to decrease with increasing intensification pressure and increase with increasing casting velocity and $\mathrm{Ku}$ mar [4] developed a multi-response optimization model of process parameters in die cast aluminum LM6 alloy by evaluating temperature of the molten metal, injection pressure of the molten metal, type of coating and type of cooling on the density, hardness and surface roughness of aluminum LM6 alloy. An experimental model for encompassing three responses namely surface roughness, density and hardness was employed to carry out the experiment and an analysis of variance (ANOVA) was performed for all the responses and the effect of the factors were explained and regression analysis was done to correlate the effect of factors with all the three responses. The result showed that higher injection pressures were more suitable in casting of aluminum alloys, also the analysis of microstructure showed structured changes observed in all samples and that porosity present in a casting generally decreases as the pressure in the die casting increases. Zhu et al. [5] conducted experiments on simulations of the effect of pressure on porosity in cast A356. The alloy was melted under vacuum and pressure was applied in the ceramic mould. The results showed that an increase in pressure reduces the amount of porosity and that the pore size distribution was shifted to smaller pores as pressure increased. Chiang et al. [6] proposed mathematical models for the modeling and analysis of the effects of machining parameters on the performance characteristics in the HPDC process of Al-SI alloys which were developed using the response surface methodology (RSM) to explain the influences of three processing parameters (die temperature, injection pressure and cooling time) on the performance characteristics of the mean particle size (MPS) of primary silicon and material hardness $(\mathrm{HBN})$ value. The experiment plan adopts the centered central composite design (CCD). 
The separable influence of individual machining parameters and the interaction between these parameters were also investigated by using analysis of variance (ANOVA). With the experimental values up to a $95 \%$ confidence interval, it was fairly well for the experimental results to present the mathematical models of both the mean particle size of primary silicon and its hardness value. Two main significant factors involved in the mean particle size of primary silicon were the die temperature and the cooling time. The injection pressure and die temperature also have statistically significant effect on microstructure and hardness.Adler et al. [7] investigated porosity defects in aluminium cast materials, and used volumetric analysis to identify gas porosity defects. They studied the effect of backscatter in their work on the ultrasonic inspection of aluminium cast materials, similarly Dahle et al. [8] conducted experiments on the effects of pressure on density and porosity in an aluminum cast by applying pressure to the riser in a permanent mold (die) and found a flat distribution this time of density rather than porosity, was observed with the pressurized riser. Ming et al. [9] conducted experiments on the effect of pressure on the mechanical properties and microstructure of $\mathrm{Al}-\mathrm{Cu}$-based alloy prepared by squeeze casting and concluded that hardness, tensile strength and ductility of ZA27 squeezed casting are greatly affected by applied pressure and primary reaction is promoted in squeeze cast ZA27 alloy that solidified at high pressure and a fine microstructure is obtained with the increase of pressure, Yoshihiko and Soichiro [10] identified the cause of porosity and took corrective action in the die-casting process. The purpose of the experiment was to evaluate the proposed fractal analysis by comparing the porosity in two types of aluminum alloy die castings manufactured by different die-casting processes and to confirm that fractal analysis of the spatial distribution of pores can quantitatively characterize the porosity. Ying-hui et al. [11] investigated microstructures and properties of die casting components with various thicknesses made of AZ91D alloy by means of a scanning electron microscope (SEM), transmission electron microscope (TEM), high-resolution transmission electron microscope (HRTEM), etc. It was concluded that mechanical properties of the die casting components mainly depend on grain size of-Mg phase. Obiekea, K. et al. [12] also conducted experiments on the influence of pressure on the mechanical properties and grain refinement of die cast aluminium A1350 alloy and concluded that Microstructures of the samples show structural changes under varying applied pressures as some appear granular, lamellar, coarse etc. and was seen that porosity susceptibility was obvious with pressure decrease in the casting process due to poor grains sizes and that hardness, Tensile strength, yield strength and elongation varied across the different applied pressures in the cast samples as values were observed to increase with pressure. $\mathrm{Li}$ Runxia et al. [13] investigated the effect of specific pressure on microstructure and mechanical properties of squeeze cast ZA27 alloy and concluded that hardness, tensile strength and ductility of ZA27 squeeze casting with high height to thickness ratio are greatly affected by pressure and that primary reaction is promoted in squeeze cast ZA27 alloy solidified at high pressure and fine microstructure is obtained with increase of pressure. 


\section{Materials and Methods}

\subsection{Materials}

The materials used in this work were Aluminum A380 alloy (mostly used in aeronautics) and A1350 alloy (used mostly for electric distribution lines).

The chemical composition of both alloys as revealed by $\mathrm{x}$-ray fluorescence test is summarized in the Table 1 below.

\subsection{Pouring and Melting}

Aluminum alloys A1350 and A380 were procured and melted in an electric furnace of capacity $500 \mathrm{~kg}$ at the Scientific and Equipment Development Institute, Enugu. (SEDI), at a temperature of $720^{\circ} \mathrm{C}$.

\subsection{Pressure Application}

A 500 ton Cold chamber die casting machine available at the scientific and equipment development institute, (SEDI), Enugu, Nigeria was used to cast the samples. The pressure was regulated across five levels by the pressure regulating valve on the die cast machine and five samples of each alloy were cast separately and the machine was operated at standard operating conditions except the pressure which was $0,350,700,1050$, and $1400 \mathrm{~kg} / \mathrm{cm}^{2}$.

\subsection{Dies for Experiment}

Dies used for the casting of top cylinders of a vulcanizing machine vailable at the Scientific and Equipment Development Institute (SEDI) Enugu were used to cast the samples and specimen were cut from them for mechanical tests and microstructure analysis.

Figure 1 shows the five samples of A1350 cast of the top cylinder of a vulcanizing machine that were die cast across the five regulated pressures with graphite oil as the coating type and oil plus water as the cooling medium. The pouring temperature, coating type and cooling medium were kept constant and only pressure was regulated as tabulated in Table 2.

Figure 2 also shows the five samples of A380 cast of the top cylinder of a vulcanizing machine that were die cast across the five regulated pressures with graphite oil as thecoating type and oil plus water as the cooling medium. The pouring temperature, coat-

Table 1. Chemical composition of work materials

\begin{tabular}{cccccccccc}
\hline & \multicolumn{8}{c}{ percentage composition } \\
\cline { 2 - 10 } & $\mathrm{Al}$ & $\mathrm{Si}$ & $\mathrm{Cu}$ & $\mathrm{Mg}$ & $\mathrm{Mn}$ & $\mathrm{Zn}$ & $\mathrm{Ni}$ & $\mathrm{Ti}$ & $\mathrm{Fe}$ \\
\hline \multirow{2}{*}{$\mathrm{A} 380$} & $\mathrm{Bal}$ & 8.50 & 3.50 & 0.05 & 0.27 & 1.80 & 0.08 & 0.05 & 1.05 \\
\hline & $\mathrm{Al}$ & $\mathrm{Si}$ & $\mathrm{Fe}$ & $\mathrm{Cu}$ & $\mathrm{Mn}$ & $\mathrm{Cr}$ & $\mathrm{Zn}$ & \multirow{2}{*}{ others } \\
\hline \multirow{2}{*}{$\mathrm{A} 1350$} & $\mathrm{Bal}$ & 0.10 & 0.40 & 0.05 & 0.01 & 0.01 & 0.05 & 0.15 \\
\hline
\end{tabular}




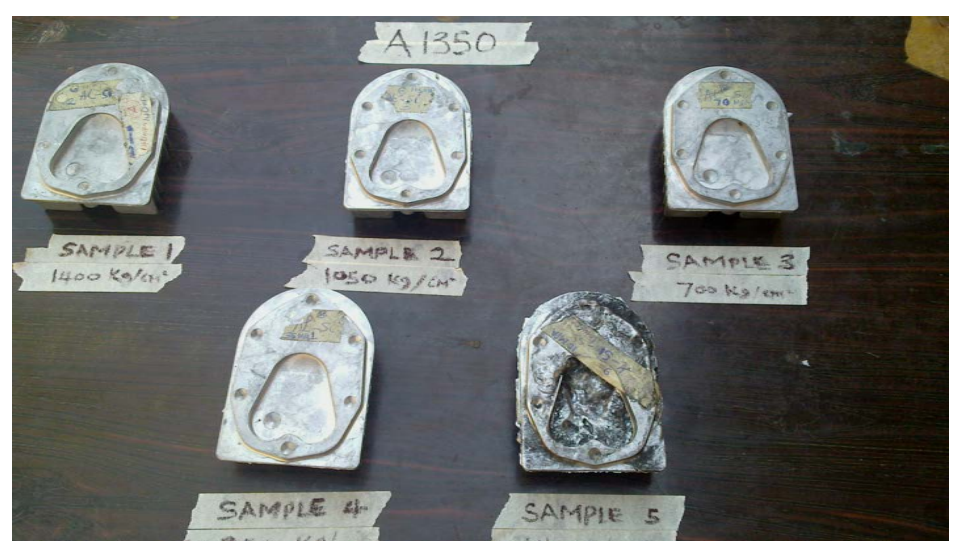

Figure 1. Samples of A1350 casts.

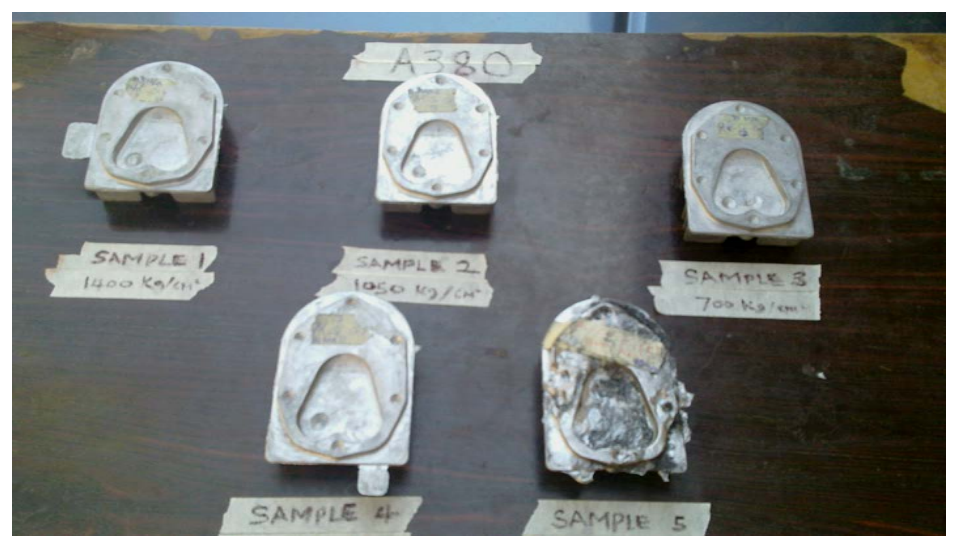

Figure 2. Samples of A380 casts.

Table 2. Input factors and their respective levels for the casts of both alloys shown above.

\begin{tabular}{ccclc}
\hline Sample No. & Pouring temp ${ }^{\circ} \mathrm{C}$ & $\begin{array}{c}\text { Injection pressure } \\
\left(\mathrm{Kg} / \mathrm{cm}^{2}\right)\end{array}$ & Coating type & Cooling medium \\
\hline 1 & 720 & 1400 & graphite oil & Water + oil \\
2 & 720 & 1050 & graphite oil & Water + oil \\
3 & 720 & 700 & graphite oil & Water + oil \\
4 & 720 & 350 & graphite oil & Water + oil \\
5 & 720 & 0 & graphite oil & Water + oil \\
\hline
\end{tabular}

ing type and cooling medium were kept constant and only pressure was regulated as tabulated in Table 2.

\subsection{Regression Models}

Regression models are used to predict one variable from one or more other variables. Regression models provide the scientist with a powerful tool, allowing predictions about past, present, or future events to be made with information about past or present events. In order to construct a regression model, both the information which is going to 
be used to make the prediction and the information which is to be predicted must be obtained from a sample of objects or individuals [14]-[16]. The relationship between the two pieces of information is then modeled with a linear transformation equation. Then in the future, only the first information is necessary, and the regression model is used to transform this information into the predicted.

Multiple regression analysis is a statistical tool for understanding the relationship between two or more variables. Multiple regressions involves a variable to be explained called the dependent variable and additional explanatory variables that are thought to produce or be associated with changes in the dependent variable Multiple regression also may be useful in determining whether or not a particular effect is present, in measuring the magnitude of a particular effect, and in forecasting what a particular effect would be, but for an intervening event [17]-[21].

The linear regression was carried out using the regression line Equation $y=a+b x$.

The constants $\mathrm{a}$ and $\mathrm{b}$ can be calculated from the expressions:

$$
\begin{gathered}
a=\frac{\left(\sum y \cdot \sum x^{2}\right)-\left(\sum x \cdot \sum x y\right)}{\left(N \sum x^{2}\right)-\left(\sum x\right)^{2}} \\
b=\frac{N \sum x y-\left(\sum x \cdot \sum x y\right)}{\left(N \sum x^{2}\right)-\left(\sum x\right)^{2}}
\end{gathered}
$$

And the multiple regression was carried out using the multiple regression Equation $y=a+b x_{1}+c x_{2}$ where the equations for the constants are:

$$
\begin{gathered}
\sum y=n a+b \sum x_{1}+c \sum x_{2} \\
\sum x_{1} y=a \sum x_{1}+b \sum x_{1}^{2}+c \sum x_{1} x_{2} \\
\sum x_{2} y=a \sum x_{1}+b \sum x_{1} x_{2}+c \sum x_{2}^{2}
\end{gathered}
$$

The RMSE of a model prediction with respect to the estimated variable $X$ model is defined as the square root of the mean squared error:

$$
R M S E=\sqrt{\frac{\sum_{i=1}^{n}\left(X_{\text {obs }, i}-X_{\text {model }, i}\right)^{2}}{n}}
$$

where Xobs is observed values and $X$ model is modeled values at time/place $i$.

\section{Results and Discussions}

\subsection{Hardness Test}

The hardness values were measured using the Rockwell hardness testing machine (model AVERY 6402 England), available at the work shop of the Science and Technology Complex (SHEDA) Abuja. The indents formed were measured on B scale with a minor load of $10 \mathrm{~kg}$, major load of $100 \mathrm{~kg}$ but before the hardness test, the surfaces of the samples were cleaned thoroughly by removing dirt, scratches and oil.

The results obtained from the hardness tests on the cast samples of both alloys are represented in Figure 3. 


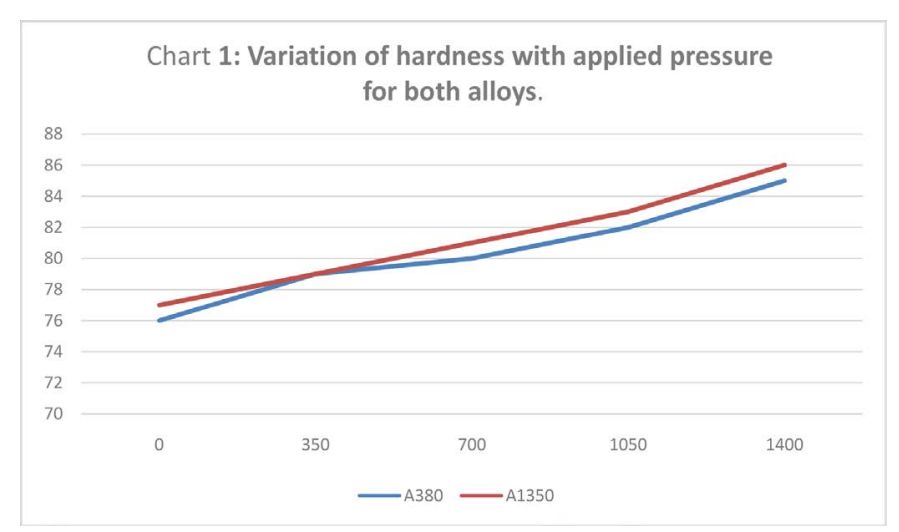

Figure 3. Variation of hardness with applied pressure for both alloys.

The figure shows that hardness values for both alloy casts follow similar pattern with increased applied pressure similar to work by Ming et al. [8]. The regression model is:

$$
\text { Hardness }_{(\mathrm{A} 380)}=76.2+0.006 P
$$

The root mean square error was found to be RMSE $=0.46$

$$
\text { Hardness }_{(\mathrm{A} 1350)}=76.8+0.062 P
$$

The root mean square error was found to be RMSE $=0.28$, where $P$ is pressure.

\subsection{Tensile Test}

The specimen bars produced from the samples of both alloys were subjected to tensile tests in accordance with the ASTM E8 standard test method for tension testing of metallic materials using a Hounsfield tensiometer with maximum load of $500 \mathrm{KN}$ available at the workshop of the Science and Technology Complex (SHEDA) Abuja, Nigeria. The test specimen size was $100.4 \mathrm{~mm}$ length and gauge length of $45 \mathrm{~mm}$ was marked on the samples. The specimen were mounted by their ends into the holding grips of the testing machine and locked securely. The machine then elongated the specimen at constant rate and at the same time the instantaneous load applied was measured using an extensometer and recorded. The results obtained from the tensile tests on the cast samples are represented below in Figure 4 and Figure 5.

The figures show that tensile strengths for both alloy castings and elongations followed similar pattern also with increase in applied pressure similar to works by Ming et al. [8]. The regression model is:

$$
\text { Tensile strength }_{(\mathrm{A} 380)}=300.2+0.026 P
$$

The root mean square error was found to be RMSE $=2.67$

$$
\text { Tensile strength }_{(\mathrm{A} 1350)}=82.4+0.014 P
$$

The root mean square error was found to be RMSE $=1.41$, where $P$ is pressure.

\section{Yield Strength Result}

The results of the yield strength obtained from the tensile tests on both alloy cast samples are represented in Figure 6. 


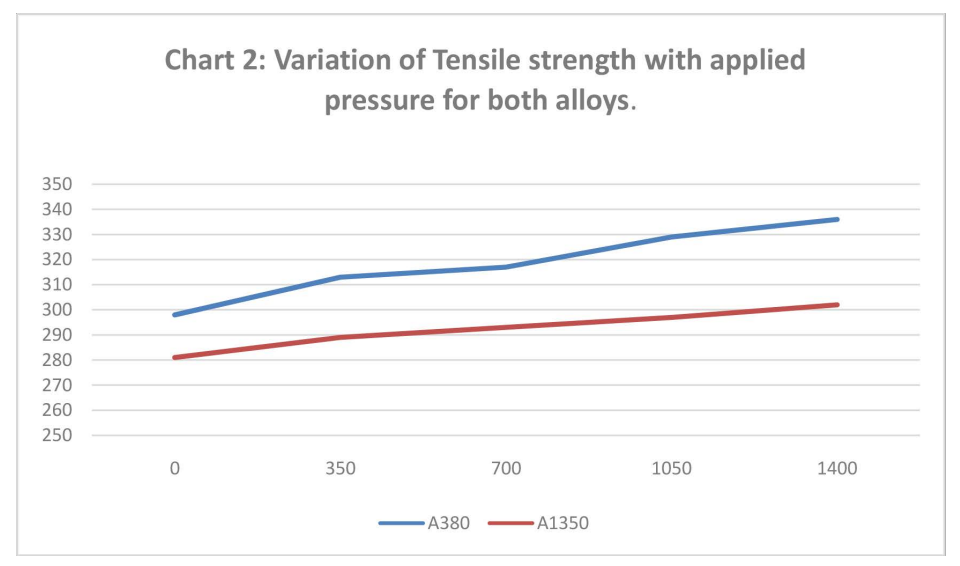

Figure 4. Variation of tensile strength with applied pressure for both alloys.

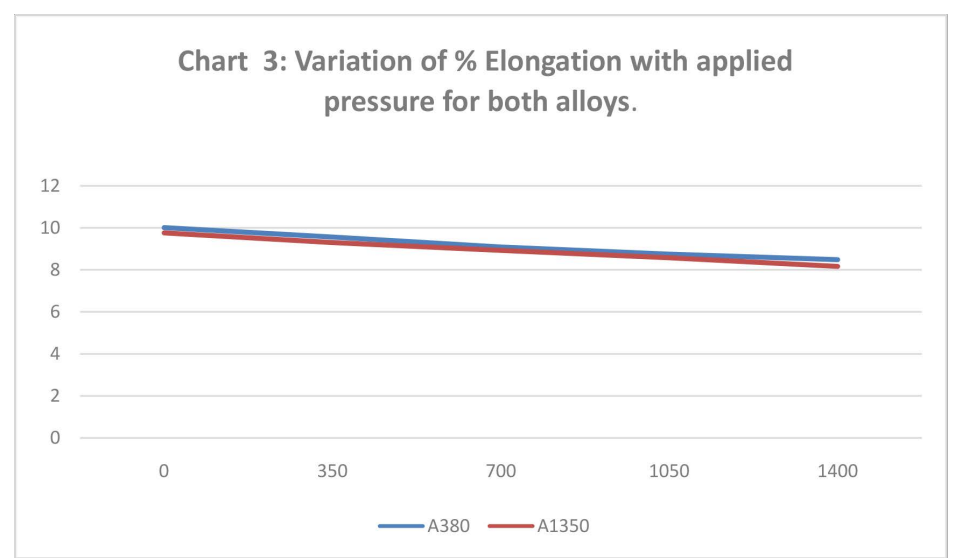

Figure 5. Variation of elongation with applied pressure for both alloys.

The figure shows that the yield strengths for both alloy casts also followed similar pattern with applied pressure.

The regression model is:

$$
\text { Yield strength }_{(\mathrm{A} 380)}=161.2+0.010 P
$$

The root mean square error was found to be RMSE $=0.06$

$$
\text { Yield strength }_{(\mathrm{A} 1350)}=125+0.020 P
$$

The root mean square error was found to be RMSE $=0.50$, where $P$ is pressure.

\subsection{Impact Test Results}

The impact tests of the samples of both alloys were conducted using the Avery Denison test machine available at the work shop of the Science and Technology Complex (SHEDA) Abuja, Nigeria. Impact tests of the samples of both alloys were carried out using the charpy $\mathrm{V}$ notch test method. All specimens were notched at the centre to about $2 \mathrm{~mm}$ depth with a root radius of $0.25 \mathrm{~mm}$ at angle of 450 according to the standard of the machine used. Impact tests conducted for each sample were in accordance with ASTM E23 "standard method for notched bar impact testing of metallic mate- 
rials". The expended energy was measured and recorded for each specimen. The results obtained from the impact strength tests are represented below in Figure 7.

The figure shows that impact strengths for both alloy casts followed similar pattern also with applied pressure. The trends are similar for the two alloys as both followed similar pattern.

The regression model is:

$$
\text { Impact strength }_{(\mathrm{A} 380)}=3.938+0.0003 P
$$

The root mean square error was found to be MSE $=0.0006$

$$
\text { mpact strength }_{(\mathrm{A} 1350)}=3.972+0.00032 \mathrm{P}
$$

The root mean square error was found to be $\mathrm{MSE}=0.00024$, where $P$ is pressure.

\section{Metallographic Examination}

Microstructures of both alloy samples were investigated by means of a scanning electron microscope (SEM) available at the physics laboratory at Science and Technology Complex (SHEDA) Abuja and the metallurgical microscope available at metallurgy laboratory available at the Federal University of Technology Minna.

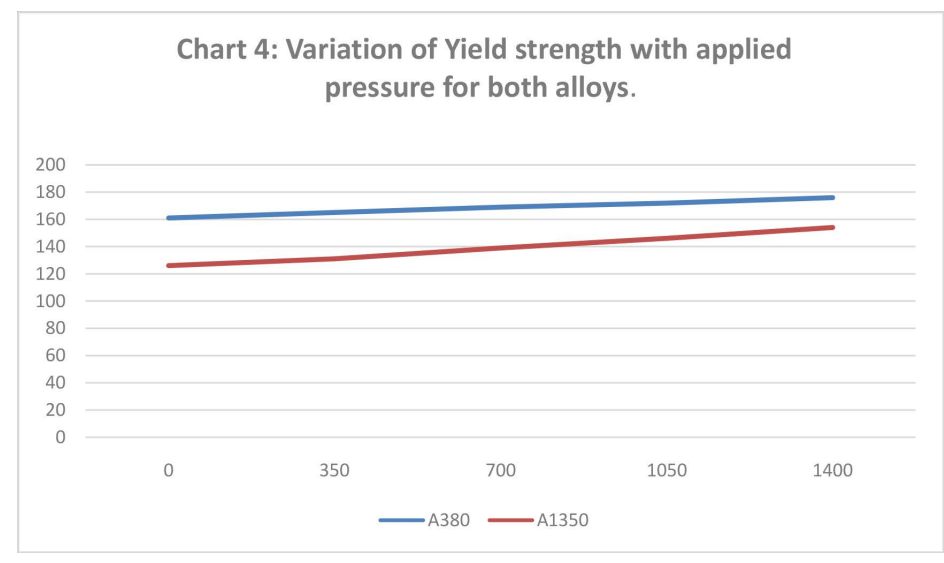

Figure 6. Variation of Yield strength with applied pressure for both alloys.

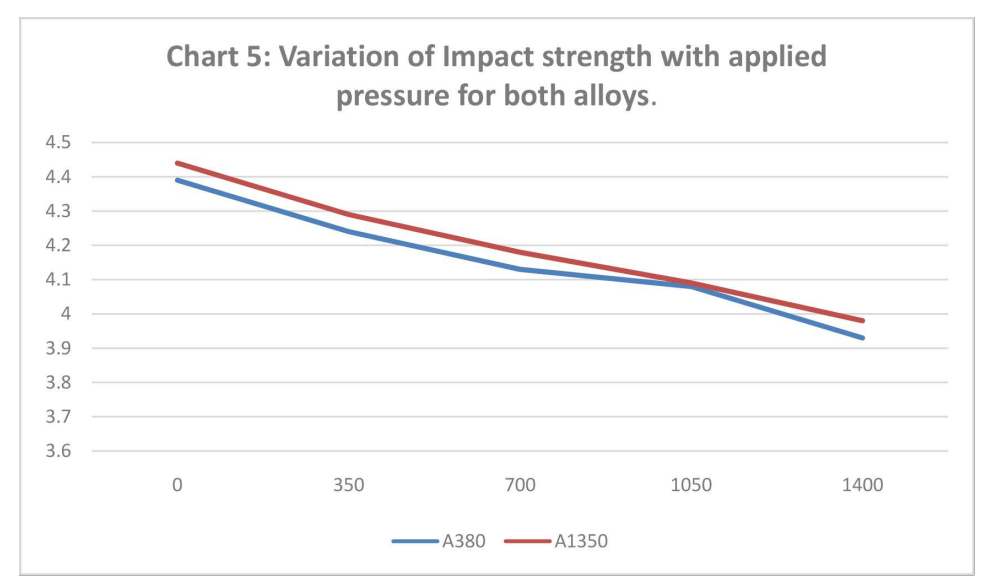

Figure 7. Variation of Impact strength with applied pressure for both alloys. 
Preparation of the samples for micro examination involved mainly sampling, polishing and etching. Samples measuring $26 \mathrm{~mm} \times 15 \mathrm{~mm} \times 5 \mathrm{~mm}$ were cut from the castings with the help of a hacksaw. The samples were filed and ground. Grinding was done in succession on a bench grinder using silicon carbide abrasive papers of 220 - 320 - 400 and 600 grits, the samples were polished in the usual manner with final polishing being carried out by hand, and they were etched in aqueous solution containing $2.5 \% \mathrm{HNO}_{3}$, $1.5 \% \mathrm{HCL}$ and $1 \% \mathrm{HF}$ acid (etched with Keller's reagent) for 20 to 60 seconds. Etching was done to make visible the grains of the samples under different pressures conditions.

\subsection{Scanning Electron Microscope Analysis (SEM)}

Microstructures of the samples were investigated by means of a scanning electron microscope (SEM) available at the physics laboratory at Science and Technology Complex (SHEDA) Abuja. Samples after preparation were placed to the multi-stub sample holder by the help of double sided conductive aluminum tape and mounted unto the sample chamber and an electron gun switched on which passed an accelerating voltage of $20 \mathrm{kv}$ and probe current of $227 \mathrm{pA}$ through the samples at a working distance of $6.0 \mathrm{~mm}$. SEM was done to make visible porosity pores across the microstructures of the samples under the different pressure conditions.

\subsection{Number of Grains}

The variations of the number of grains with applied pressure are presented in Figure 8 for both alloys. As shown in the figure, number of grains also followed similar pattern in both alloy casts with applied pressure as they both showed variations in the number of grains across the varying applied pressures similar to work by ying-hui et al. [10].

The regression model is:

$$
\text { Number of grains }_{(\mathrm{A} 380)}=28.726+0.048 P
$$

The root mean square error was found to be MSE $=7.35$

$$
{\text { Number of } \text { grains }_{(\mathrm{A} 1350)}=28.018+0.049 P}
$$

The root mean square error was found to be MSE $=6.86$, where $P$ is pressure.

\subsection{Grain Size}

Figure 9 shows the variation also of grain sizes with varying pressure for both alloys. The figure shows that finer grains were obtained with increased applied pressure as the trend are also similar and followed same pattern in both alloy castings similar to work by Ying hui et al. [10].

The regression model is:

$$
\text { Grain Size }_{(\mathrm{A} 380)}=10.6-0.00343 P
$$

The root mean square error was found to be $\mathrm{MSE}=0.28$

$$
\text { Grain Size }_{(\mathrm{A} 1350)}=10.8-0.004 P
$$




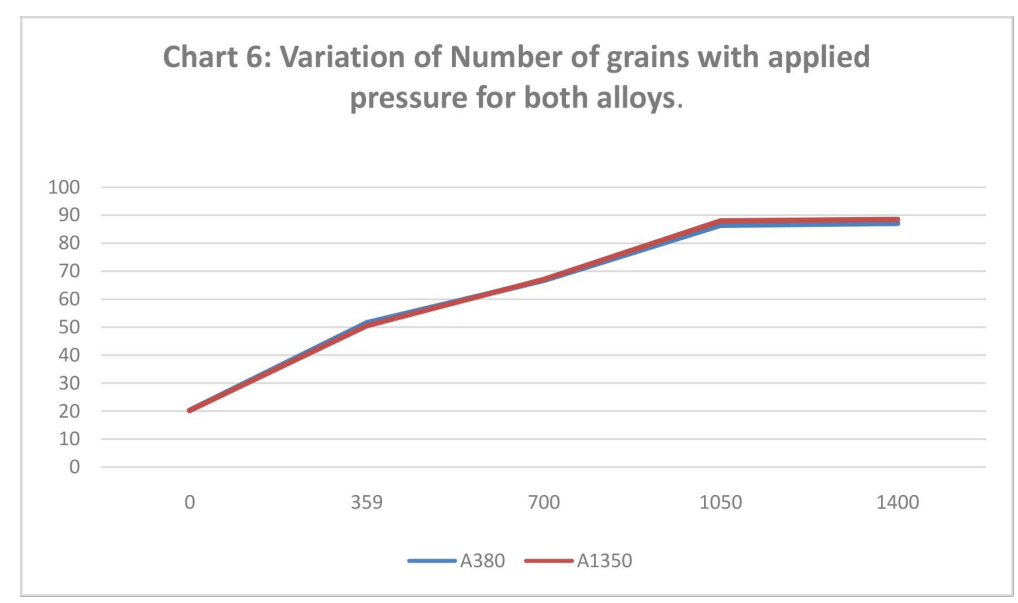

Figure 8. Variation of number of grains with applied pressure for both alloys.

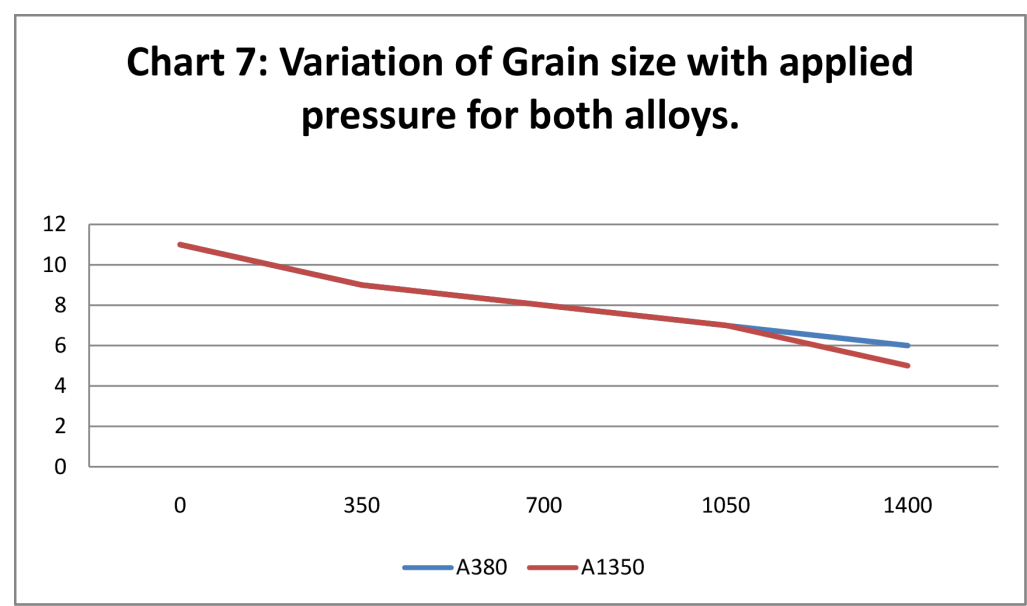

Figure 9. Variation of grain size with applied pressure for both alloys.

The root mean square error was found to be MSE $=0.28$, where $P$ is pressure.

\subsection{Microstructure Analysis}

The microstructures of the samples of both alloys at varying pressures consisted of a primary $\alpha$ phase, peritectic $\beta$ phase and ternary eutectic phase $(\beta+\eta+\varepsilon)$, where $\alpha$ phases appeared as nodular when the pressure reached $1400 \mathrm{~kg} / \mathrm{cm}^{2}$ (seen in Figure $10)$, also the eutectic structure $(\beta+\eta+\varepsilon)$ was not found in the samples at $1400 \mathrm{~kg} / \mathrm{cm}^{2}$, while the $(\eta+\varepsilon)$ phases appeared between grains. The primary $\alpha$ phases appeared as elongated at $1050 \mathrm{~kg} / \mathrm{cm}^{2}$ pressure (seen in Figure 11) and with $700 \mathrm{~kg} / \mathrm{cm}^{2}$ pressure, $\alpha$ phases solidified as coarse grains and the eutectic structure $(\beta+\eta+\varepsilon)$ phases appeared between grains (Figure 12).

In the lower pressure samples, scanty grains were seen and they were not homogeneously distributed (Figure 13 and Figure 14). In the solidification process of both alloys, the primary phase $\alpha$ precipitates first from liquid phase and then the hypoeutectic reaction follows. However, at high pressure, the degree of these two reactions becomes 
A380

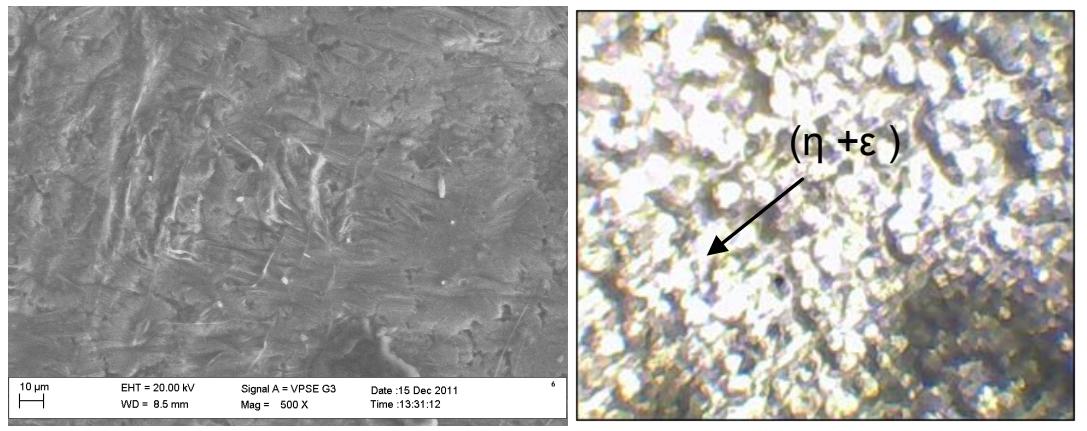

A1350
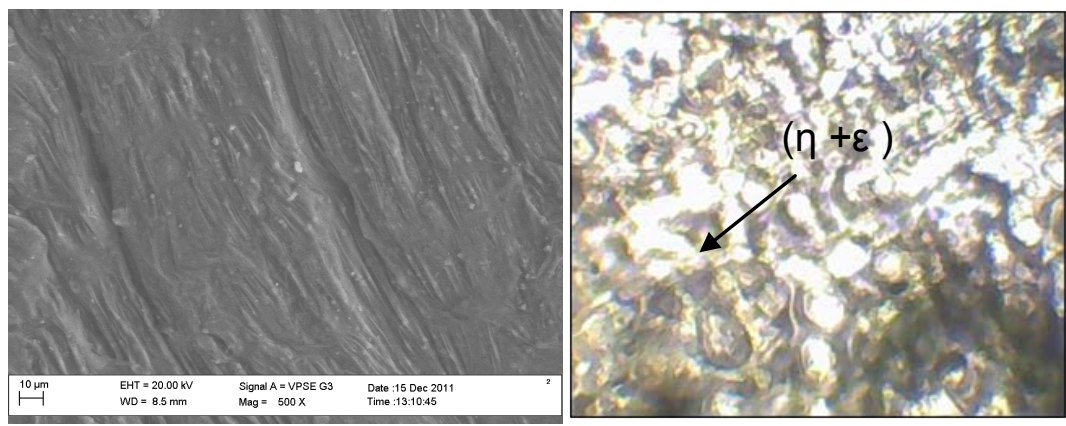

Figure 10. SEM (Scanning Electron Microscope) and DEM (Digital Electron Microscope) of sample 1 of both alloys with pressure of $1400 \mathrm{Kg} / \mathrm{cm}^{2}$.

A380
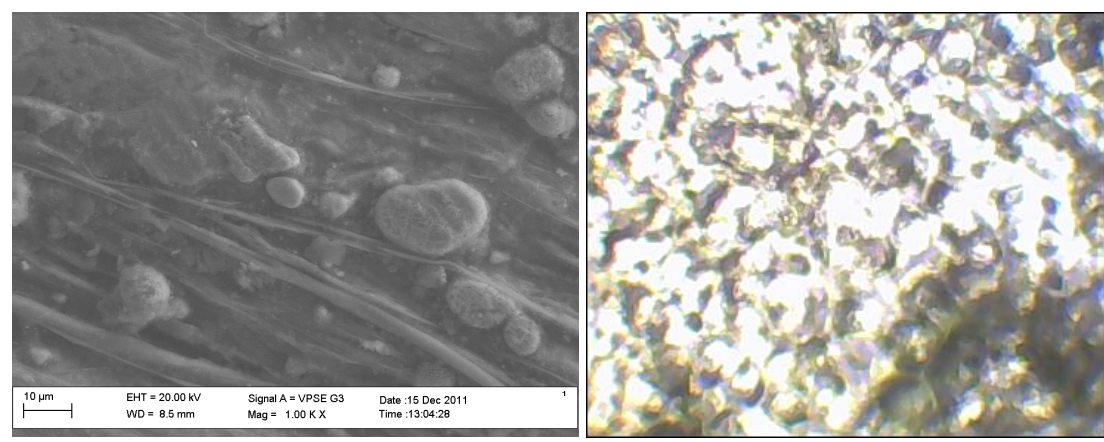

A1350
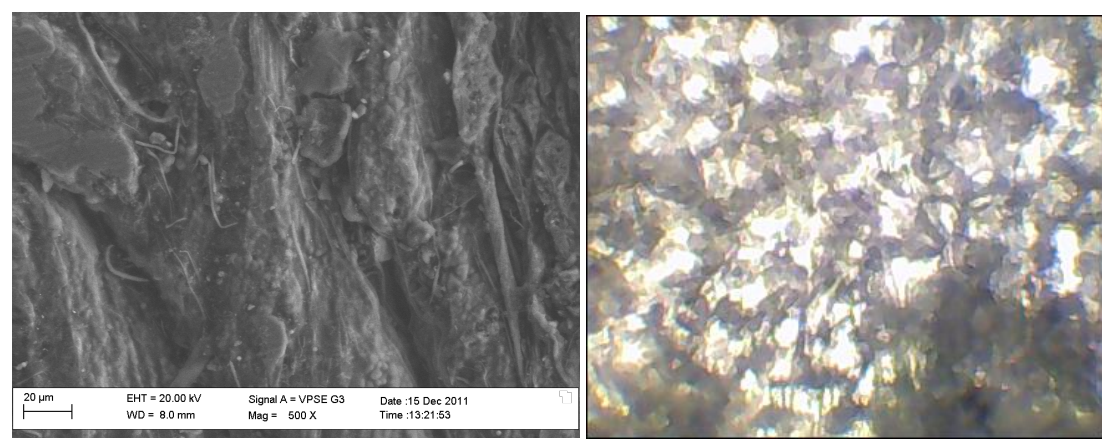

Figure 11. SEM (Scanning Electron Microscope) and DEM (Digital Electron Microscope) of sample 2 of both alloys with pressure of $1050 \mathrm{Kg} / \mathrm{cm}^{2}$. 
greater due to the fact that the eutectic point in both alloys moves to the direction of rich $\mathrm{Al}$, thus the quantity of remaining liquid phase is reduced greatly. On the other hand, because the melting points of both alloys are elevated at high pressure, the degree of super-cooling increases, thus the nucleate rate of primary reaction increases largely during solidifying. This is also the reason for microstructure refining, In addition, the remaining phase is in deep super-cooling state when temperature is dropped to the eutectic point. Therefore, the improvement of mechanical properties is attributed to eliminating of micro-pores in the alloys caused by higher pressure. On the other hand, it is because of the microstructure refining as the applied pressure is increased that increased tensile strength and hardness are attributed to. It can be deduced that the eutectic reaction was restrained while the primary reaction was promoted in both alloys at higher pressure similar to works by [8] [10].

In Figure 10 and Figure 11 above, at pressures of $1400 \mathrm{~kg} / \mathrm{cm}^{2}$ the SEM and DEM of both alloys samples showed fine grain structures that produced elongated pattern and the grains were finely and cohesively arranged. The much concentrated grains were cohesively arranged and evenly distributed due to good compatibility of the grain structure which is absolutely, evenly distributed in an attractive manner and perfectly embedded with one another and as pressure was being lowered to $1050 \mathrm{~kg} / \mathrm{cm}^{2}$ in Figure 11, the SEM and DEM of both alloys showed spherical dimples characteristics of grain types and showing also fine grains and also the much concentrated grains were cohesively arranged and evenly distributed.

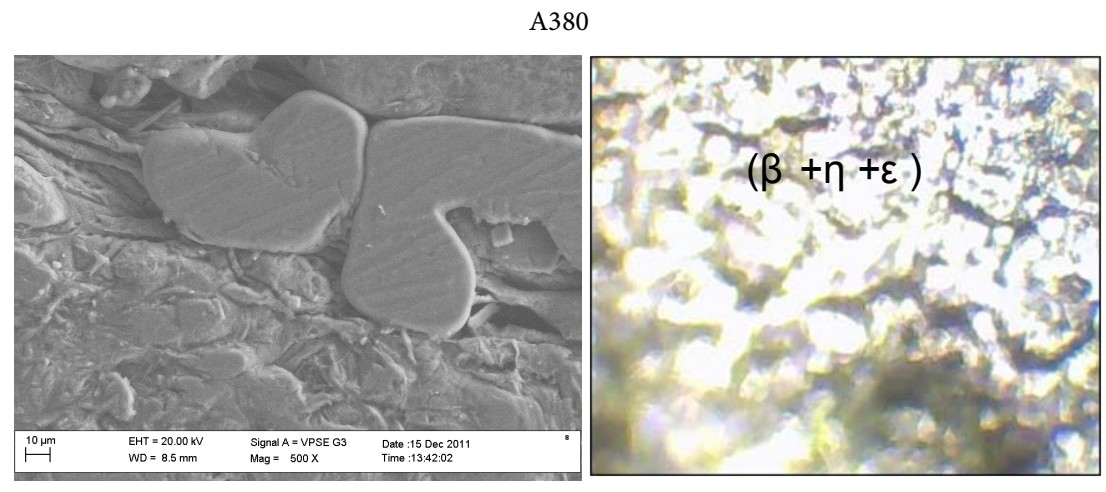

A 1350
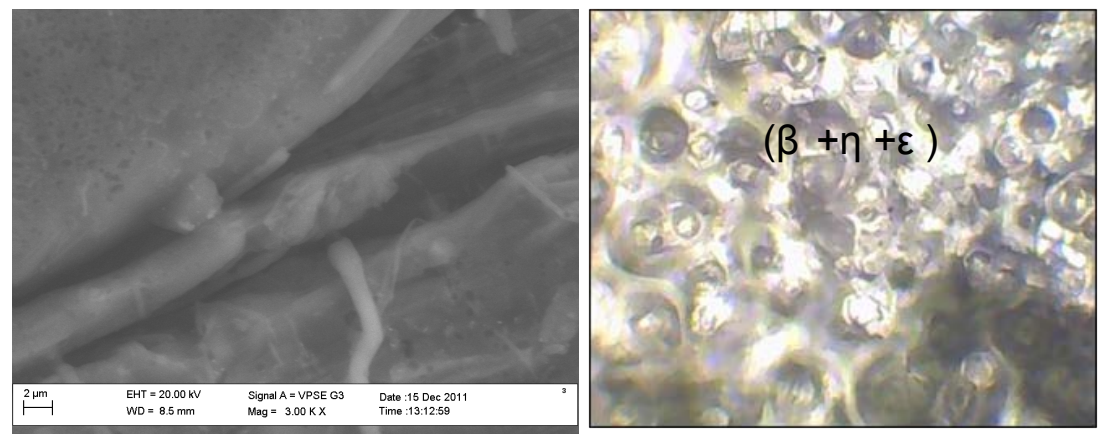

Figure 12. SEM (Scanning Electron Microscope) and DEM (Digital Electron Microscope) of sample 3 of both alloys with pressure of $700 \mathrm{Kg} / \mathrm{cm}^{2}$. 


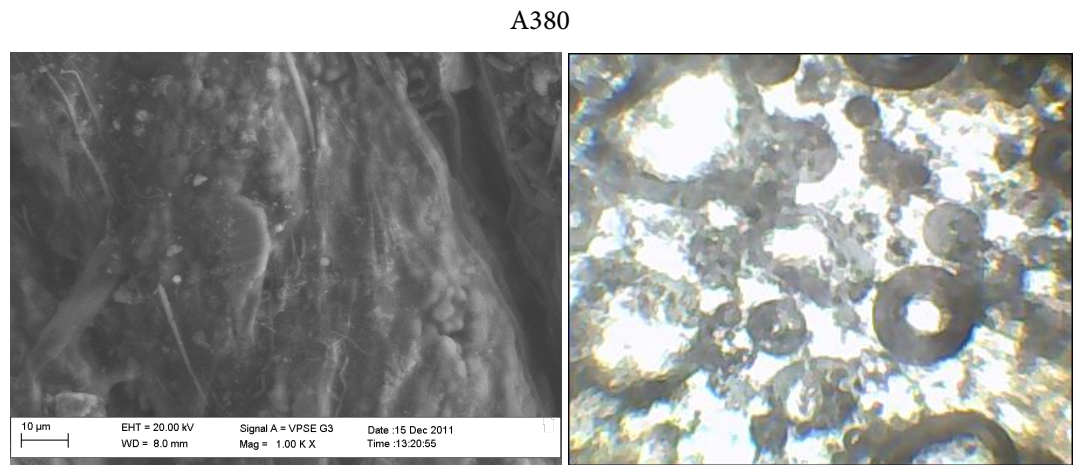

A1350
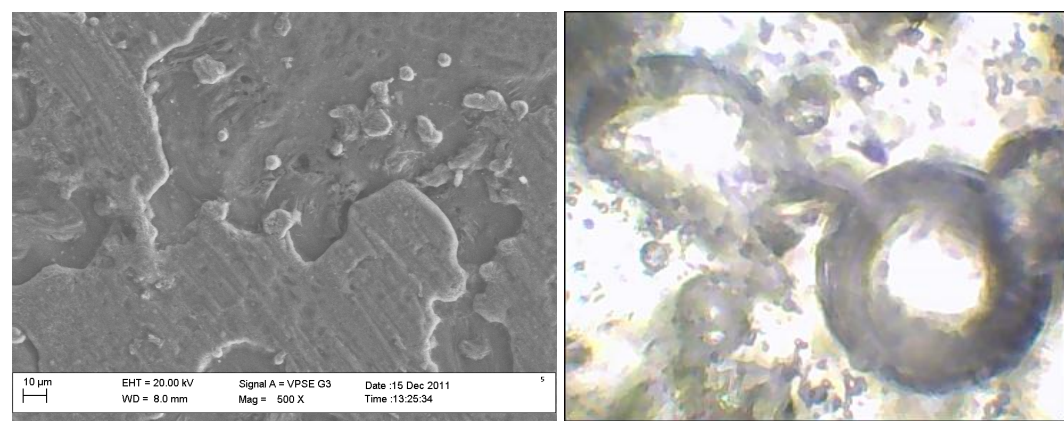

Figure 13. SEM (Scanning Electron Microscope) and DEM (Digital Electron Microscope) of sample 4 of both alloys with pressure of $350 \mathrm{Kg} / \mathrm{cm}^{2}$.

In Figure 12, as the pressure was further lowered to $700 \mathrm{~kg} / \mathrm{cm}^{2}$, the microstructure of both alloy samples showed that the grains were cohesively arranged and appeared in parabolic-shaped characteristic appearance. The SEM and DEM show also, ductile aluminum of transgranular fracture surface leaving spaces between the grains which obviously show not very fine grains.

In Figure 13, as the pressure was lowered to $350 \mathrm{~kg} / \mathrm{cm}^{2}$, the micrograph of both alloys samples showed spherical characteristic of grain types showing big grain sizes. It was also clearly shown that the grains were scanty because of coarse grain sizes that depict porosity susceptibility over time.

In Figure 14 at gauge pressure, the microstructure and micrograph of both alloys samples showed deformation that is worsened and the degree of deformation so great. The grains clearly show no morphology that is obvious, probably due to low pressure. The microstructure clearly shows obvious porosity in the sample that solidified at low pressure.

\section{Conclusions}

Based on the investigation results, the following conclusions can be drawn:

1) The hardness of both alloys varied in similar manner with pressure as the hardness values of both alloys increased with increase in applied pressure. Also the model that was fitted to the experimental data showed linear relationship with the actual data in view of the small error generated by them. 
A380
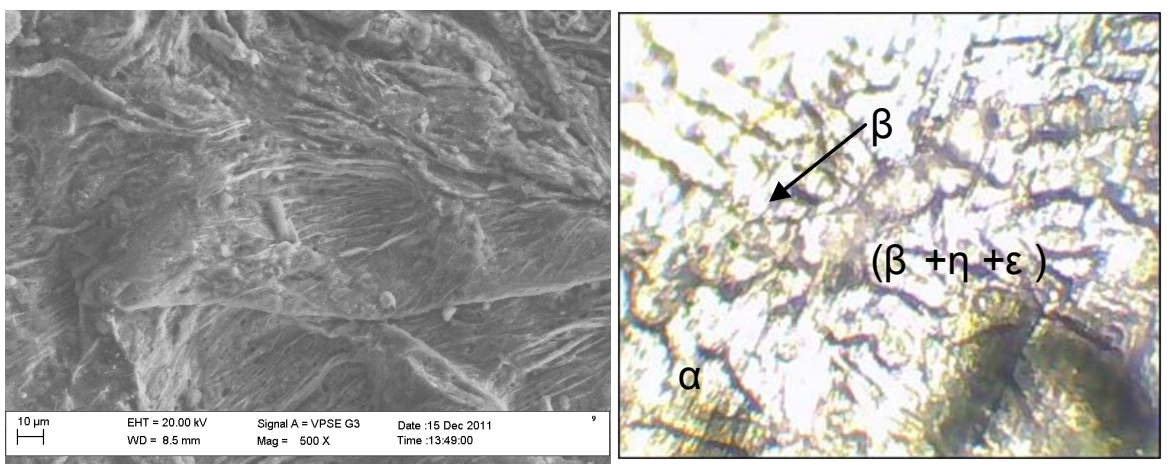

A 1350
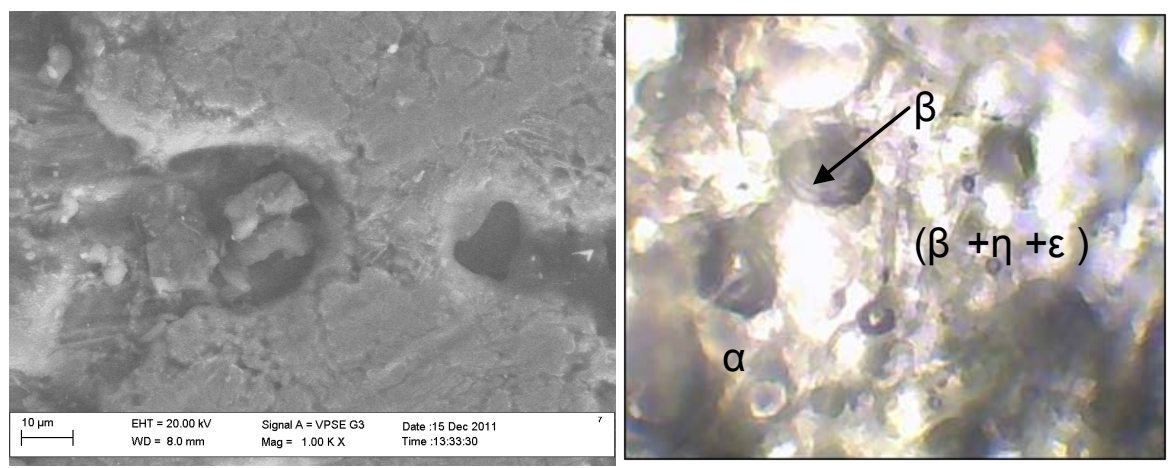

Figure 14. SEM (Scanning Electron Microscope) and DEM (Digital Electron Microscope) of sample 5 of both alloys with pressure of $0 \mathrm{Kg} / \mathrm{cm}^{2}$.

2) Tensile and yield strengths of both alloys also varied in similar manner with pressure as both strengths increased with increase in applied pressure. Also the model that was fitted to the experimental data showed linear relationship with the actual data in view of the small error generated by them.

3) The impact strengths of both alloys were observed to vary in similar manner across the different applied pressures in the casting process as the impact strengths of both alloys increased with applied pressure. Also the model that was fitted to the experimental data showed linear relationship with the actual data in view of the small error generated by them.

4) The number of grains increased with applied pressure for both alloys. Also the grains became finer with applied pressure for both alloys. The model that was fitted to the experimental data showed linear relationship with the actual data in view of the small error generated by them.

5) The SEM and DEM showed different morphologies that were distributed across the samples of both alloys under varying applied pressures as both showed structural changes (granular, lamellar, coarse etc.) due to pressure variation. The fine grains which were homogenously distributed on micrographs of both alloys at $1400 \mathrm{~kg} / \mathrm{cm}^{2}$ can effectively block the movement of dislocations, thus increase the strength and plasticity of both alloys. 
6) For all the models developed, a close relationship with the experimental results were underlying in view of the small errors generated by them and can be used to predict the experimental values of this research.

\section{References}

[1] Doehler, H. (1910) Art of and Apparatus for Casting Fluid Metal, United States Patent 973483. United States Patent and Trademark Office, Washington DC.

[2] Doehler, H. (1951) Die Casting. McGraw Hill Book Company, New York.

[3] Matthew, S., Dargusch, A., Dourb, G., Schauer, C., Dinnis, C.M. and Savaged, G. (2006) The Influence of Pressure during Solidification of High Pressure Die Cast Aluminium Telecommunication Components. Journal of Materials Processing Technology, 180, 37-43. http://dx.doi.org/10.1016/j.jmatprotec.2006.05.001

[4] Kumar, L. (2010) Multi-Response Optimization of Process Parameters in Cold Chamber Pressure Die Casting. M.ENG Thesis, Mechanical Engineering Department, Thapar University, India.

[5] Zhu, J.D., Cockcroft, S.L. and Maijer, D.M. (2006) Modeling of Micro Porosity Formation in A356 Aluminum Alloy Casting. Metallurgical and Materials Transactions A, 37A, 1075. http://dx.doi.org/10.1007/s11661-006-0080-4

[6] Chiang, K.-T., Liu, N.-M. and Tsai, T.-C. (2008) Modeling and Analysis of the Effect of Processing Parameters on the Performance Characteristics in the High Pressure Die Casting Process of Al-Sl Alloys. International Journal of Advanced Manufacturing Technology, 41, 1076-1084.

[7] Adler, L., Nagy, P.B., Rypien, D.V. and Rose, J.H. (1989) Ultrasonic Evaluation of Porosity in Aluminium Cast Materials. Ohio State University, Columbus.

[8] Dahle, A.K., Arnberg, L. and Apelian, D. (1997) Burst Feeding and Its Role in Porosity Formation during Solidification of Aluminum Foundry Alloys, 101st Casting Congress. American Foundry Men's Society, Seattle.

[9] Zhang, M., Zhang, W.-W., Zhao, H.-D., Zhang, D.-T. and Li, Y.-Y. (2007) Effect of Pressure on Microstructures and Mechanical Properties of Al-Cu-Based Alloy Prepared by Squeeze Casting. Transactions of Nonferrous Metals Society of China, 17, 496-501. http://dx.doi.org/10.1016/S1003-6326(07)60122-8

[10] Yoshihiko, H. and Soichiro, K.B. (2009) Quantitative Evaluation of Porosity in Aluminum Alloy Die Castings by Fractal Analysis of Spatial Distribution of Area. Materials and Design, 30, 1169-1173. http://dx.doi.org/10.1016/j.matdes.2008.06.025

[11] Wei, Y.H., Hou, L.F., Yang, L.J., Xu, B.S., Kozuka, M. and Ichinose, H. (2009) Microstructure and Properties of Die Casting Components with Various Thickness made of AZ91D alloy. Journal of Materials Processing Technology, 209, 3278-3284. http://dx.doi.org/10.1016/j.jmatprotec.2008.07.034

[12] Obiekea, K., Aku, S.Y. and Yawas, D.S. (2012) The Influence of Pressure on the Mechanical Properties and Grain Refinement of Die Cast Aluminium A1350 Alloy. Journal of Advances in Applied Science Research, 3, 3663-3673.

[13] Li, R.D., et al. (2003) Effect of Super-High Pressure on the Non-Equilibrium Solidified Microstructure and Mechanical Properties of ZA27 Alloy. Foundry, 52, 92-94.

[14] James, W.H. (1996) Modeling Biological Systems: Principles and Applications. Springer, 186-189.

[15] Cha, P.D., Rosenberg, J.J. and Dym, C.L. (2000) Fundamentals of Modeling and Analyzing 
Engineering Systems. Cambridge University Press, New York.

[16] Weisberg, S. (1985) Applied Linear Regression. 2nd Edition, John Wiley \& Sons, New York.

[17] Rubinfeld, D.L. and Steiner, P.O. (1983) Quantitative Methods in Antitrust Litigation, Law \& Contemp. Probs.

[18] Cook, R.D. (1979) Influential Observations in Linear Regression. Journal of the American Statistical Association, 74, 169-174. http://dx.doi.org/10.1080/01621459.1979.10481634

[19] Draper, N. and Smith, H. (1981) Applied Regression Analysis. 2nd Edition, New York.

[20] Allen, D.M. (1971) Mean Square Error of Prediction as a Criterion for Selecting Variables. Technometrics, 13, 469-475. http://dx.doi.org/10.1080/00401706.1971.10488811

[21] Aris, R. (1994) Mathematical Modeling Techniques. New York.

\section{Submit or recommend next manuscript to SCIRP and we will provide best service} for you:

Accepting pre-submission inquiries through Email, Facebook, LinkedIn, Twitter, etc. A wide selection of journals (inclusive of 9 subjects, more than 200 journals)

Providing 24-hour high-quality service

User-friendly online submission system

Fair and swift peer-review system

Efficient typesetting and proofreading procedure

Display of the result of downloads and visits, as well as the number of cited articles Maximum dissemination of your research work

Submit your manuscript at: http://papersubmission.scirp.org/

Or contact jmmce@scirp.org 